\title{
TRANSITIONAL CELL CARCINOMA OF FALLOPIAN TUBE: A CASE REPORT
}

Anju Vij ${ }^{1}$, Neelam Mahajan ${ }^{2}$, Amit Gupta ${ }^{3}$, Rajinder Kumar ${ }^{4}$, Renu Sharma ${ }^{5}$

\section{HOW TO CITE THIS ARTICLE:}

Anju Vij, Neelam Mahajan, Amit Gupta, Rajinder Kumar, Renu Sharma. "Transitional Cell Carcinoma of Fallopian Tube: A Case Report". Journal of Evolution of Medical and Dental Sciences 2015; Vol.4, Issue 48, June 15;

Page: 8408-8411, DOI:10.14260/jemds/2015/1217

ABSTRACT: Transitional carcinomas are extremely rare in the fallopian tube.A 68 year old para four presented to Gynecology outpatient department with history of menopause for last 16 years, postmenopausal bleeding for last 22 days and no history of vaginal discharge. There was a history of similar complaints 12 years back. She was not investigated then. In view of two episodes of postmenopausal bleeding and USG suggestion of? Polyp? endometrial thickening and inconclusive histopathological report of endometrial curetting, patient was posted for total abdominal hysterectomy with bilateral salpingo-oopherectomy. Histopathological report came out to be transitional cell carcinoma of fallopian tube. She received 6 cycles of chemotherapy and is on regular follow up with no complaints.

KEYWORDS: Post-menopausal bleeding, Fallopian tube carcinoma, Transitional cell carcinoma, Total abdominal hysterectomy with bilateral salpingo-oopherectomy, Chemotherapy.

INTRODUCTION: Primary fallopian tube cancer is a rare malignancy. It is commonly confused clinically with ovarian mass. The commonest clinical features are clear or blood stained discharge per vaginum and abdominal pain. As the fallopian tube distends with the mass, the patient has severe abdominal pain and thus presents earlier to the clinician. However thorough clinical examination may still not enable a preoperative diagnosis and thus intra-operative inspection becomes very important to label it as of primary tubal origin. The management is similar to epithelial ovarian cancer. It carries a better prognosis than ovarian tumours as it tends to be diagnosed early and has a better five year survival rate.

CASE SUMMARY: A 68 year old para 4 was admitted from the Gynecology outpatient department, Dr. R. P. G. M. C. Tanda, Distt. Kangra, H. P., with the chief complaint of Postmenopausal bleeding for 22 days. Bleeding was dark red, scanty, soaking one pad per day and not responding to medications.

No complaint of discharge per vaginum.

No urinary or bowel complaint.

She had attained Menopause 16 years back. She was parafour with all full term vaginal deliveries. There was no history of any other major illness and her personal history \& family history was not significant. Patient gave history of similar complaints 12 years back but was not investigated then. No complaint since then.

INVESTIGATIONS: ULTRASOUND: Uterus small, atrophic, 58x41x19 mm. in size. Appears to be normal. The evidence of hypoechoic area $22 \times 6 \mathrm{~mm}$ in upper endometrial cavity suggestive of? polyp? Endometrial thickening:

Bilateral adenexa normal.

FRACTIONAL CURETTAGE done.

Scanty curettings obtained. 


\section{CASE REPORT}

On HPE, Autolytic changes with few inflammatory changes seen. (Inconclusive)

In view of two episodes of postmenopausal bleeding and USG suggestion of? polyp? Endometrial thickening, she was posted for total abdominal hysterectomy and bilateral salpingooopherectomy.

\section{IN SITU:}

- Uterus small menopausal size.

- Left fallopian tube showing hematosalpinx of $5 \times 2 \mathrm{cms}$.

- Left ovary normal.

- Right tube and ovary normal.

- Peritoneal surfaces normal.

- Omentum normal looking.

- No free fluid in pelvis.

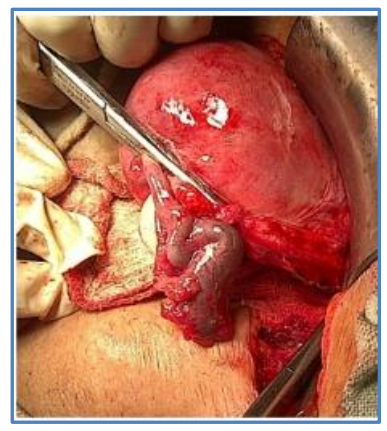

\section{Fig. 1}

\section{HISTOPATHOLOGY:}

- Specimen- uterus $6 \times 3.5 \times 2 \mathrm{cms}$ in size.

- Left Fallopian tube dilated and measured $1.5 \mathrm{~cm}$ in diameter and $9 \mathrm{~cm}$ in length.

- Cut section- lumen filled with grey white tumour.

\section{HISTOPATHOLOGY:}

TRANSITIONAL CELL CARCINOMA: Muscularis was attenuated, no invasion into muscularis. Tumor composed of cells with coffee-bean like nuclei arranged in solid nests without keratinization suggestive of transitional cell histology.

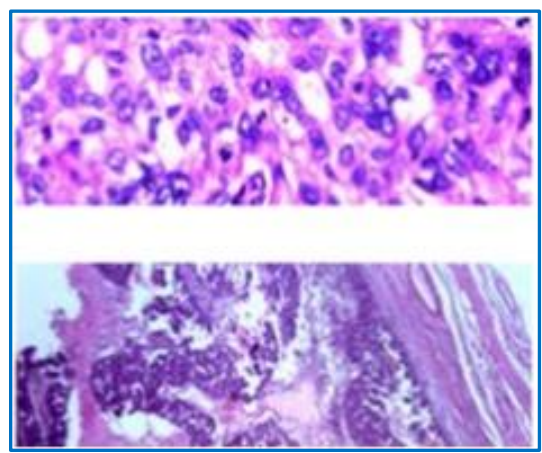

Fig. 2

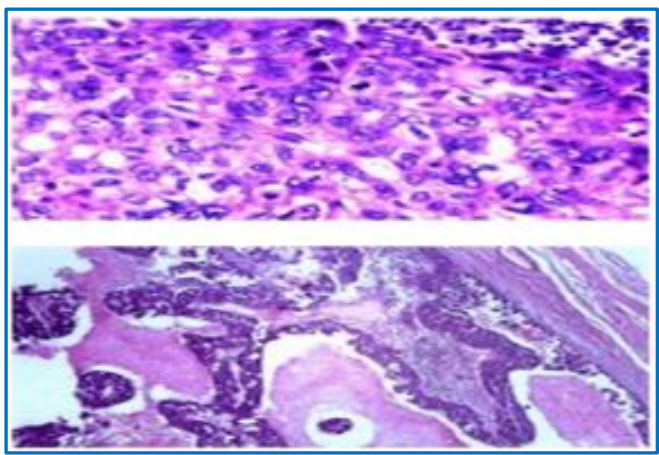

Fig. 3 
Ovary and contralateral adenexa along with endometrium and cervix were free of tumour.

Patient received six cycles of Cisplatin based chemotherapy three weekly. At present she has no complaints and is under surveillance.

DISCUSSION: Incidence of fallopian tube carcinoma is $0.5 \%$ of all gynaecological malignancies. ${ }^{1}$

Largest series was of 3051 cases by Stewart et al. ${ }^{2}$

- $88 \%$ - adenocarcinoma.

- $89 \%$ - unilateral.

- Rare varieties - leiomyosarcoma, transitional cell carcinoma.

Latzko triad (15\%).3-4

- Intermittent watery discharge (hydrops tubal profulens).

- Colicky abdominal/pelvic pain.

- Abdominal/ pelvic mass.

Primary fallopian tube carcinoma (PFTC), first described by Renaud in 1847, is the least common gynecological malignancy encountered in practice. Though histologically and clinically, fallopian tube carcinoma resembles epithelial ovarian cancer (EOC), transitional cell carcinoma of the fallopian tube is a very rare histological variant, with only around 20 cases having been reported worldwide so far. ${ }^{5-6}$

CA-125 is also found to be a good marker for post-treatment follow-up, similar to ovarian carcinoma. ${ }^{7}$ Optimally cytoreduced patients with primary fallopian tube carcinoma treated with a paclitaxel-based chemotherapy regimen have an excellent possibility of survival. ${ }^{8}$

\section{STAGING OF FALLOPIAN TUBE CARCINOMA:}

Stage I: Tumor limited to one or both tubes, with or without ascites.

Stage II: Tumor involves one or both tubes with pelvic extension and/or metastasis to the uterus or ovary or extension to other pelvic tissues.

Stage III: Tumor involves one or both tubes with peritoneal implants outside the pelvis and/or regional nodes.

Stage IV: Distant metastasis outside the peritoneal cavity.

\section{MANAGEMENT:}

- Same as that of epithelial ovarian cancers, i.e.,

- Exploratory laparotomy to remove the primary disease + staging and debulking.

- Cisplatin and Paclitaxel based chemotherapy.

- 5 year survival rates of $40 \%$ are better than ovarian cancers.

\section{REFERENCES:}

1. Fallopian tube carcinoma: A review. Pectasides D, Pectasides E, Economopoulos T, Oncologist. 2006 Sep; 11 (8): 902-12.

2. The incidence of primary fallopian tube cancer in the United States. Stewart SL, Wike JM, Foster SL, Michaud F. Gynecol Oncol. 2007 Dec; 107 (3): 392-7. Epub 2007 Oct. 24.

3. Callahon TL, Caughey AB, Blueprinys obs. \& gyne. Lippincott Williams \& wilkins (2008) ISBN: 078178249. 
4. Gibbs RS, Danforth DN, Karlon BY et al. Danforth's obs. \& gynecology Lippincott W@illiams \& Wilkins (2008) ISBN: 078176937.

5. Gupta N, Srinivasan R, Nijhawan R, Dhaliwal LK. Primary fallopian tube carcinoma with exfoliation of malignant cells in cervical Pap smear. Cytojournal. 2005; 2: 20. [PMC free article] [PubMed].

6. Chin H, Matsui H, Mitsuhashi A, Nagao K, Sekiya S. Primary transitional cell carcinoma of the fallopian tube: A case report and review of literature. Gynecol Oncol. 1998; 71: 469-75. [PubMed].

7. Pectasides D, Pectasides E, Economopoulos T. Fallopian tube carcinoma: A review. Oncologist. 2006; 11: 902-12. [PubMed].

8. Paclitaxel-based chemotherapy in carcinoma of the fallopian tube. Gemignani $\mathrm{ML}^{1}$, Hensley ML, Cohen R, Venkatraman E, Saigo PE, Barakat RR. GynecolOncol. 2001 Jan; 80 (1): 16-20.

\section{AUTHORS:}

1. Anju Vij

2. Neelam Mahajan

3. Amit Gupta

4. Rajinder Kumar

5. Renu Sharma

\section{PARTICULARS OF CONTRIBUTORS:}

1. Associate Professor, Department of Obstetrics \& Gynaecology, DRPGMC, Tanda, Kangra District, H. P.

2. Professor, Department of Obstetrics \& Gynaecology, DRPGMC, Tanda, Kangra District, H. P.

3. Associate Professor, Department of Obstetrics \& Gynaecology, DRPGMC, Tanda, Kangra District, H. P.
4. Professor, Department of Obstetrics \& Gynaecology, DRPGMC, Tanda, Kangra District, H. P.

5. Assistant Professor, Department of Obstetrics \& Gynaecology, DRPGMC, Tanda, Kangra District, H. P.

\section{NAME ADDRESS EMAIL ID OF THE CORRESPONDING AUTHOR:}

Dr. Anju Vij, Department of Obstetrics \& Gynaecology, DRPGMC, Tanda, Kangra District, H. P.

E-mail: doctors_vij@yahoo.com

Date of Submission: 12/05/2015. Date of Peer Review: 13/05/2015. Date of Acceptance: 06/06/2015. Date of Publishing: 15/06/2015. 